\title{
The mabA gene from the inhA operon of Mycobacterium tuberculosis encodes a 3-ketoacyl reductase that fails to confer isoniazid resistance
}

\author{
Asesh Banerjee, ${ }^{1} \uparrow$ Michele Sugantino, ${ }^{2}$ James C. Sacchettini ${ }^{2} \ddagger$ \\ and William R. Jacobs, Jr ${ }^{1}$
}

Department of

Microbiology and

Immunology', Howard

Hughes Medical Institute,

and Department of

Biochemistry22, Albert

Einstein College of

Medicine, Bronx,

NY 10461, USA
Author for correspondence: William R. Jacobs, Jr. Tel: +1 718430 2888. Fax: +1 7185180366. e-mail: jacobs@aecom.yu.edu
Keywords: Mycobacterium tuberculosis, isoniazid, ethionamide, drug resistance, inhA gene

\section{INTRODUCTION}

Tuberculosis is one of the world's most deadly infectious diseases (World Health Organization, 1997). The recent emergence of multidrug-resistant strains of Mycobacterium tuberculosis poses a serious threat to tuberculosis-control programs worldwide (Snider et al., 1994). Understanding the mechanisms of resistance to the available antimycobacterial drugs and discovery of new drug targets are necessary for the treatment of tuberculosis.

The gene (inhA) encoding a target for isoniazid (INH) and its analogue, ethionamide $(\mathrm{ETH})$, was cloned in

\footnotetext{
†Present address: Laboratory of Bacterial Pathogenesis and Immunology, Rockefeller University, New York, NY 10021, USA.

¥Present address: Department of Biochemistry and Biophysics, Texas A\&M University, College Station, TX 77843, USA.

Abbreviations: CAT, chloramphenicol acetyltransferase; ER, enoyl reductase; ETH, ethionamide; INH, isoniazid; KAR, 3-ketoacyl reductase.

The GenBank/EMBL accession numbers for the sequences reported in this paper are U66800 (M. smegmatis mabA) and U66801 ( $M$. tuberculosis mabA). The mabA sequence from $M$. bovis BCG is identical to that of $M$. tuberculosis.
}

1994 (Banerjee et al., 1994). Mutations in inhA were shown to confer resistance to both INH and ETH in drug-resistant $M$. tuberculosis clinical isolates (Heym et al., 1994; Kapur et al., 1996; Musser et al., 1996; Ristow et al., 1995; Rouse et al., 1995; Telenti et al., 1997; Victor et al., 1997). KatG- (Zhang et al., 1992) activated INH is proposed to inhibit the inbA-encoded enoyl reductase (ER) enzyme, which is involved in the biosynthesis of mycolic acids (long-chain fatty acids of mycobacteria) (Johnsson et al., 1995; Wheeler \& Anderson, 1996; Quemard et al., 1995; Dessen et al., 1995; Rozwarski et al., 1998).

An ORF has been found immediately upstream of inhA in all the mycobacteria tested thus far (Banerjee et al., 1994). This ORF, a strong homologue of many 3ketoacyl reductases (KARs), was previously designated orf1 and later renamed mabA (Musser et al., 1996), due to its probable involvement in mycolic acid biosynthesis (Kikuchi et al., 1989; Quemard et al., 1995). mabA from Mycobacterium smegmatis, which is transcribed separately from inhA, has been shown not to mediate INH-ETH resistance. Despite the fact that, unlike in $M$. smegmatis, mabA constitutes an operon with inhA in 
M. tuberculosis, it was not initially tested whether MabA from M. tuberculosis plays a role in mediating drug resistance. Based on the high ( $82 \%$ identity) homology between these two MabAs, it was assumed that $M$. tuberculosis MabA is not involved in $\mathrm{INH}$ resistance. However, later on, INH-resistant clinical isolates of $M$. tuberculosis were frequently reported to have mutations in the ribosome-binding site (RBS) of mabA (Kapur et al., 1996; Musser et al., 1996; Rouse et al., 1995; Telenti et al., 1997; Victor et al., 1997). This observation supported the speculation that, in $M$. tuberculosis, MabA could be an additional target for INH and ETH, and overexpression of MabA could mediate INH resistance by virtue of increased drug titration (Musser, 1995). Hence, we decided to characterize the mabA-encoded activity and examined, by a genetic approach, whether it can be a target for INH and ETH in M. tuberculosis.

\section{METHODS}

Strains, plasmids and media. Strains and plasmids used in this study are shown in Table 1 . All the antibiotics used were purchased from Sigma if not mentioned otherwise. Luria broth (Difco) and Luria agar containing $50 \mu \mathrm{g}$ ampicillin $\mathrm{ml}^{-1}$ were used for the growth of Escherichia coli strains (Sambrook et al., 1989). Mycobacteria were grown in liquid culture using M-OADC-TW broth (Jacobs et al., 1991). Middlebrook 7H10 agar (supplemented with $10 \%$ OADC and $0.5 \%$ glycerol) was used for growth on solid media, colony titrations and plating transformations of mycobacteria. Selections for mycobacteria were performed using this solid medium containing kanamycin $\left(10-25 \mu \mathrm{g} \mathrm{ml}^{-1}\right)$, INH $\left(0 \cdot 2,1,10,20\right.$ and $\left.50 \mu \mathrm{g} \mathrm{ml}^{-1}\right)$ and ETH $\left(10,30,50,100\right.$ and $\left.200 \mu \mathrm{g} \mathrm{ml}^{-1}\right)$. Cycloheximide was added to liquid and solid media at a final concentration of $50 \mu \mathrm{g} \mathrm{ml}^{-1}$ to inhibit growth of moulds.

DNA manipulation, cloning and sequencing. The original $M$. smegmatis mabA-inhA cosmids were isolated from a $M$. smegmatis genomic library by their ability to confer INH resistance in the $M$. smegmatis host (Banerjee et al., 1994). Analogous M. tuberculosis and Mycobacterium bovis BCG cosmids were obtained by screening genomic libraries of these two organisms using colony blotting. The plasmids used in this study (Table 1) are subclones of these parent cosmids. For subcloning, cosmid DNAs were digested with the restriction enzymes (New England Biolabs) indicated in Table 1, and the desired DNA fragments were isolated by using the GENECLEAN II kit (Bio 101) after electrophoresis on a $1 \%$ SEAKEM (FMC) agarose gel following the manufacturer's

Table 1. Strains and plasmids used in this study

\begin{tabular}{|c|c|c|}
\hline Strain or plasmid & Genotype/phenotype/description & Reference/source \\
\hline \multicolumn{3}{|l|}{ Strains } \\
\hline E. coli $\mathrm{DH} 5 \alpha$ & $\mathrm{F}^{-}$endA1 hsdR17 supE44 thi-1 recA1 gyrA96 relAD(argF-lacZYA)U169 & $\begin{array}{l}\text { Bethesda Research } \\
\text { Laboratories }\end{array}$ \\
\hline $\begin{array}{l}\text { E. coli Epicurian } \\
\text { Coli SCS1 }\end{array}$ & 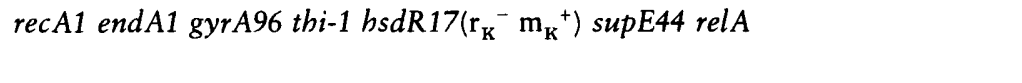 & Stratagene \\
\hline $\begin{array}{l}\text { E. coli } \\
\text { BL21(DE3)pLysS }\end{array}$ & 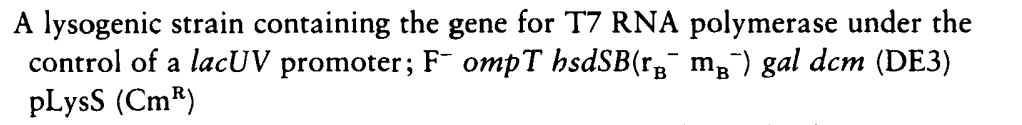 & Novagen \\
\hline $\begin{array}{l}\text { M. smegmatis } \mathrm{mc}^{2} 6 \\
\text { ATCC607 }\end{array}$ & $\begin{array}{l}\text { Wild-type strain from which the M. smegmatis mabA and inhA genes were } \\
\text { cloned }\end{array}$ & $\begin{array}{l}\text { W. Jones, Centers for Disease } \\
\text { Control, Atlanta, GA, USA }\end{array}$ \\
\hline $\begin{array}{l}\text { M. smegmatis } \\
\mathrm{mc}^{2} 155\end{array}$ & Electroporation-efficient mutant of $\mathrm{mc}^{2} 6$, wild-type for drug-resistance & Snapper et al. (1990) \\
\hline $\begin{array}{l}\text { M. bovis } \\
\text { BCGPasteur }\end{array}$ & Wild-type & $\begin{array}{l}\text { World Health Organization, } \\
\text { Geneva }\end{array}$ \\
\hline $\begin{array}{l}\text { M. tuberculosis } \\
\text { H37Rv TMC102 }\end{array}$ & Wild-type, causes disease in guinea pigs & Trudeau Institute \\
\hline \multicolumn{3}{|l|}{ Plasmids } \\
\hline pMD31 & $\begin{array}{l}\text { E. coli-mycobacteria shuttle plasmid vector with blue/white selection, } \\
\sim 7 \mathrm{~kb} \text {, derivative of pUC119 }\end{array}$ & Donnelly-Wu et al. (1993) \\
\hline pBluescript II KS $(+)$ & E. coli sequencing vector with blue/white selection & Stratagene \\
\hline pET3d & E. coli expression vector with $\mathrm{T} 7$ promoter & Novagen \\
\hline pET3d-mabA & $\mathrm{pET} 3 \mathrm{~d}:: 744 \mathrm{bp}$ mabA PCR fragment from M. tuberculosis $\mathrm{H} 37 \mathrm{Rv}$ & This work \\
\hline pYUB376 & $\begin{array}{l}\text { pMD31::3.5 kb Nhel insert containing } M . \text { tuberculosis } \mathrm{H} 37 \mathrm{Rv} \text { mabA and } \\
\text { inhA genes }\end{array}$ & Banerjee et al. (1994) \\
\hline pYUB630 & $\begin{array}{l}\text { pYUB } 376 \text { derived, insert DNA } 3^{\prime} \text { to inhA removed by digestion with } \mathrm{XbaI} \\
\text { and HindIII (Fig. 4) }\end{array}$ & This work \\
\hline pYUB631 & $\begin{array}{l}\text { Dpnl fragment carrying the CAT gene (Bartolome et al., 1991) inserted into } \\
\text { the } S p h \mathrm{I} \text { site of } m a b A \text { of pYUB630 (Fig. 4) }\end{array}$ & This work \\
\hline pYUB632 & $\begin{array}{l}\text { Derivative of pYUB376 with a truncated inhA gene produced by digestion } \\
\text { with BsaBI and HindIII (Fig. 4). }\end{array}$ & This work \\
\hline pYUB633 & As pYUB630 except that the XbaI-HindIII fragment is from M. bovis BCG & This work \\
\hline
\end{tabular}


recommendations. Purified DNA fragments were ligated into appropriate cloning vectors (Table 1) using T4 DNA ligase (New England Biolabs) to obtain the subclones. The $\mathrm{CaCl}_{2}$ facilitated transformations of DNA into E. coli DH5 $\alpha$ were done following standard protocols (Sambrook et al., 1989). DNA was electroporated into $M$. smegmatis following a previously published protocol (Snapper et al., 1990). Chromosomal DNA for PCR experiments and Southern blots was obtained from mycobacterial cells by chemical disruption of cell walls using the protocol of van Soolingen et al. (1991). DNA sequencing was performed on double-stranded DNA templates using the Automated Taq DyeDeoxy Sequencing kit (Applied Biosystems) following the manufacturer's protocols. A Perkin-Elmer model 480 Thermal Cycler was used for PCR reactions and Applied Biosystems PRISM 373 sequencing apparatus was used for DNA sequencing. All DNAs were sequenced on both strands. Nucleotide sequence was compiled and analysed using the Genetics Computer Group sequence analysis software (Genetic Computer Group, 1995). mabA genes were translated using the TRANSLATE program to obtain the amino acid sequences of the putative MabA proteins and the peptide sequences were aligned using the Megalign program of the Lasergene software package (DNAstar).

Construction of the MabA-overproducing plasmid pET3dmabA. The mabA gene product from $M$. tuberculosis was overproduced using the T7 polymerase system, as described previously (Studier et al., 1990). The mabA gene was subcloned into the pET3d vector by PCR using Taq DNA polymerase (Perkin Elmer). Restriction sites were introduced at both ends of the amplified sequence to facilitate cloning. PCR was performed on plasmid pYUB376 template DNA. The $\mathrm{N}$-terminal primer contained the first $24 \mathrm{bp}$ of the mabA coding sequence and an $\mathrm{Ncol}$ restriction site overlapping the initiation codon. The C-terminal primer contained a HindIII restriction site, the termination codon and 20 bp of the mabA anti-codon sequence. The PCR reactions contained $6 \mathrm{ng}$ template DNA, $1.5 \mu \mathrm{g}$ each primer, $200 \mu \mathrm{M}$ dNTPs, $10 \mu \mathrm{l} 10 \times$ buffer for $\mathrm{Taq}$ polymerase, 5 units $\mathrm{Taq}$ polymerase, $7 \mathrm{mM}$ $\mathrm{MgCl}_{2}$ and $10 \%$ DMSO (Perkin Elmer) in a total volume of $100 \mu$ l. The reactions were incubated at $94{ }^{\circ} \mathrm{C}$ for $1.5 \mathrm{~min}$, $62{ }^{\circ} \mathrm{C}$ for $1.5 \mathrm{~min}$ and $72{ }^{\circ} \mathrm{C}$ for $1.5 \mathrm{~min}$ for 30 cycles. The products were separated on a $1 \%$ SEAKEM agarose (FMC) gel and a $744 \mathrm{bp}$ PCR product was recovered using the GENECLEAN II kit (BIO 101).

The PCR product was cut with NcoI and HindIII and ligated into the previously cut and gel-purified pET3d (Table 1) at room temperature overnight. The ligation mixture was used to transform supercompetent Epicurian Coli SCS1 cells and colonies resistant to $50 \mu \mathrm{g}$ ampicillin $\mathrm{ml}^{-1}$ were selected. The plasmid was isolated from selected colonies and analysed for the presence of a $744 \mathrm{bp}$ insert by $1 \%$ agarose gel electrophoresis. The resulting plasmid with the 744 bp insert was transformed into the T7 polymerase containing BL21(DE3)pLysS host cells (Table 1).

Overexpression of MabA protein and the assay for KAR activity. Six litres of terrific broth [12 $\mathrm{g}$ bacto-tryptone (Difco), $24 \mathrm{~g}$ yeast extract (Difco), $0.4 \%(\mathrm{v} / \mathrm{v})$ glycerol, $0.17 \mathrm{M}$ $\mathrm{KH}_{2} \mathrm{PO}_{4}$ and $0.72 \mathrm{M} \mathrm{K}_{2} \mathrm{HPO}_{4}$ ] containing $50 \mu \mathrm{g}$ ampicillin $\mathrm{ml}^{-1}$ and $34 \mu \mathrm{g}$ chloramphenicol $\mathrm{ml}^{-1}$ was inoculated with $120 \mathrm{ml}$ overnight culture. The cells were grown at $37^{\circ} \mathrm{C}$ to an $\mathrm{OD}_{600}$ of approximately 0.7 . IPTG was added to a final concentration of $1 \mathrm{mM}$ to induce transcription of the $\mathrm{T} 7$ polymerase. The cells were harvested by centrifugation at 5000 r.p.m. (Sorvall GS-3 rotor) $2 \cdot 5 \mathrm{~h}$ after induction. Cells were resuspended in lysis buffer containing $50 \mathrm{mM}$ Tris $/ \mathrm{HCl}$, $\mathrm{pH} 8 \cdot 0,1 \mathrm{mM}$ EDTA, $0.5 \%$ Nonidet P-40 and $10 \mathrm{mM}$ DTT
(Sigma). The suspension was recentrifuged at 20000 r.p.m. for $1 \mathrm{~h}$ in a Sorvall SS-34 rotor at $4{ }^{\circ} \mathrm{C}$ to remove the cell debris. Nucleic acids were removed from the cell-free extract by $1 \%$ streptomycin sulfate precipitation, followed by centrifugation at 20000 r.p.m. in a Sorvall SS-34 rotor for $1 \mathrm{~h}$ at $4^{\circ} \mathrm{C}$. The resulting supernatant was dialysed against $20 \mathrm{mM}$ TAE, $\mathrm{pH} 7 \cdot 8$, overnight at $4{ }^{\circ} \mathrm{C}$. The resulting soluble extracts were analysed by gel electrophoresis using $10-15 \%$ gradient polyacrylamide PhastGel (Pharmacia) along with the LMW molecular mass standard (Pharmacia).

KAR assays were performed in a quartz cuvette at $30^{\circ} \mathrm{C}$ in a final volume of $1 \mathrm{ml}$ with the following components: $1 \mathrm{mM}$ acetoacetyl-CoA (Sigma), $40 \mathrm{mM}$ HEPES, pH 7.0, and $150 \mu \mathrm{M}$ NADH or NADPH. Normalized enzyme samples $(20 \mu \mathrm{l})$ from induced or uninduced cellular extracts mentioned above were added to the reaction mixture. The conversion of NADH or NADPH to NAD or NADP was measured spectrophotometrically as the reduction in $A_{340}$ by a continuous scanning method using a UVIKON 933 spectrophotometer (Kontron Instruments). The activity tests were then repeated with increasing concentrations of the induced extract using NADPH. Thereafter, initial velocities ( $\mu \mathrm{mol}$ NADPH $\mathrm{min}^{-1}$ ) of these reactions were plotted as a function of cell extract concentration. The volume of the extract used from the induced cells was $10,15,20$ and $30 \mu \mathrm{l}$. The assays were repeated on the same extracts without the acetoacetyl-CoA substrate and without the NADH/NADPH cofactor as appropriate controls.

Determination of the MIC of INH and ETH to mycobacterial strains. MIC assays were performed following a modification of our previously published assay (Banerjee et al., 1994). In short, mycobacterial cells bearing the indicated plasmids were grown in M-OADC-TW containing kanamycin $\left(15 \mu \mathrm{g} \mathrm{ml}^{-1}\right)$ and dilutions were plated on $7 \mathrm{H} 10$ agar plates containing kanamycin $\left(15 \mu \mathrm{g} \mathrm{ml}^{-1}\right)$ alone or kanamycin with various concentrations of INH or ETH. The strains without any plasmid were grown in M-OADC-TW broth, and dilutions were plated on 7H10 agar plates and 7H10 agar plates containing various concentrations of INH or ETH. Here, MIC is defined as the concentration of the drug that produced $>99 \%$ inhibition of bacterial growth when inocula of $\sim 1000$ organisms were plated. Similar sized inocula were used in every assay because MICs to INH and ETH vary considerably with large variations in inoculum.

\section{RESULTS}

\section{Cloning and characterization of mabA genes from $M$. smegmatis, $M$. tuberculosis and $M$. bovis BCG}

The report of cloning the inhA gene indicated the presence of an ORF, orf $1 / m a b A$, upstream of inhA in M. tuberculosis, M. bovis and M. smegmatis (Banerjee et al., 1994). Also, in that report, subcloning analysis demonstrated that, unlike in $M$. smegmatis, these two genes form an operon in M. tuberculosis and M. bovis. Cosmid clones were identified at that time which contained both mabA and inhA from these bacteria. In this study, parts of these cosmid inserts containing mabA were subcloned into pBluescript II $\mathrm{KS}(+)$ (Table 1) and the sequence upstream of $\operatorname{inh} A$ was determined (Fig. 1). We compared these sequences with each other, as well as with the recently released $m a b A$ sequence (accession no. AF002133) from Mycobacterium avium. The DNA region between the end of mabA and the 


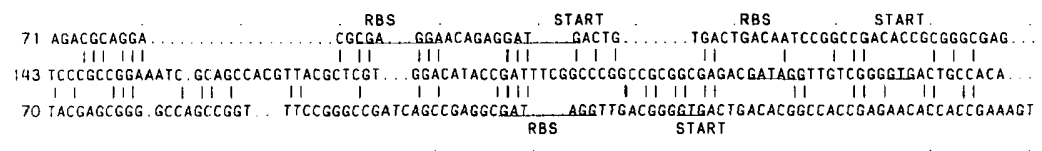

135 GCCACTGCAGG CCGCCCGGCGTTCGTCTCCCGTICGGTGCTGGTGACGgGGGTAACCGGGCAICGGCCYGGCGATCGCGCGACGGCTGGCCGCCG

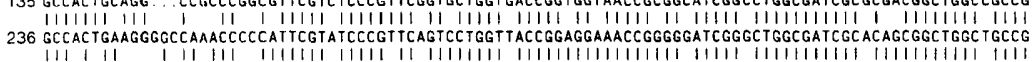

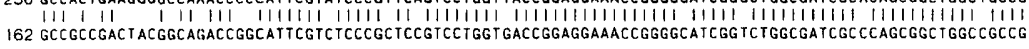
232 ACGGGCACAAGG TGGCLGGTCACCCACCGCGGTTCCGGTGCACCCGACGACCTGTTCGGTGTTCAATGTGACGTCACCGACAGCGCTGGTGTEGACCGCGC

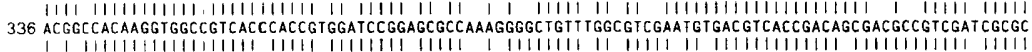
262 AGGCCCACAAGGTGGCGGTACGCACCGCGATCCGGGGGCCCGACGGG TGTTCGGTGCGAGTGCGACGTCACCGACACGACGCCGTCGACCGCGC 332 CTICAAAGAGGTCGAGGAGCACCAGGGCCCGGTCGAGGTGCTGGTGGCCAACGCAGGCATCTCCAAGGACGCATTCCTCATGCGCATGACCGAGGAGCGG 436 CTTCACGGCGGTAGAAGAGCACCAGGGTCCGGTCGAGGTGCTGGTGTCCAACGCCGGCC TATCCGCGGACGCATTCC TCATGCGGATGACCGAGgAAAAG

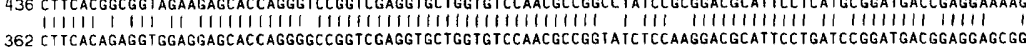
432 IICGAAGAGg TCATCAACACCAACC TCACGgGCGCGTTCGGGGCGCCCAGCGGGCGTCGCGCACCATGCAGCGCAAGCGGTTCGGCGCATCATCTTCA

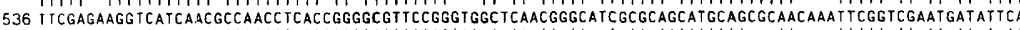

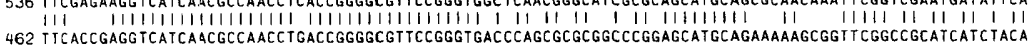
532 TCGGGTCGGTCTCGGG =ATGTGGGGGATCGGCAATCAGGCCAACTACGCGGCCGCCAAGGCGGGCC TGATCGGCATGGCCCGCTCGATCTCCCGTGAGCT 636 TAGGTTCGGTCTCCGG AGC IGGGGCATCGGCAACCAGGCCAACTACGCAGCCTCCAAGGCCGGGTGATTGGCATGGCCCGCTGGATCGCCCGCGAGC)

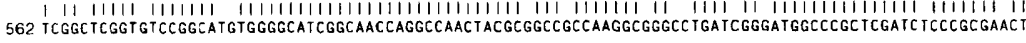
632 GGACAAGGCGGGGGTCACGGCGAACGTGTIGCCCCCCGGTTACATCGACACCGAGATGACCCGGGCGCTCGACGAGCGCATCCAGGGGGCGCGATCGAC

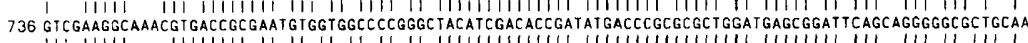

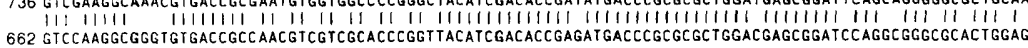
732 TICATCCCGGACAAGCGGGTCGGCACGgTCGAGgAGGTCGCGGGCGCGGTCAGCTTCC TGGCCTCGGAGGACGCCTCCTACATCGCGGGCGCGgTCATCC 836 IITATCCCAGCGAGCGGG 111111111111111111111111111111111111111111111111 1 1111111111111111111

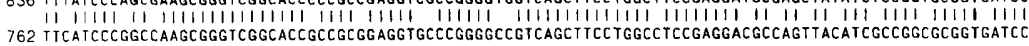

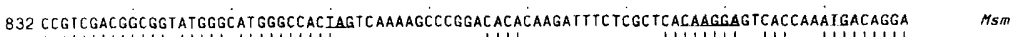

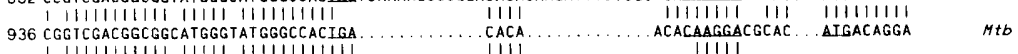

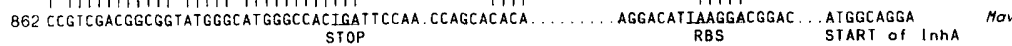

\begin{abstract}
Fig. 1. DNA sequence similarity between the mabA genes from $M$. smegmatis $\mathrm{mc}^{2} 155, M$. tuberculosis H37Rv and $M$. bovis BCG. The top sequence is of the mabA gene from $M$. smegmatis (Msm). The middle sequence is of the mabA gene from $M$. tuberculosis (Mtb). The $M$. bovis mabA sequence is not shown separately because it is identical to the mabA sequence from $M$. tuberculosis. The bottom sequence is of the mabA gene from M. avium (Mav). START, hypothetical translation start site; RBS, putative ribosome-binding site; STOP, hypothetical translation termination site. These sites are marked by underlines. Vertical bars between bases indicate identity; dots indicate gaps in the alignment. The base positions are indicated on the left. $M$. smegmatis mabA may also start from the GTG two codons downstream from the designated start.
\end{abstract}

beginning of inhA from $M$. avium is more similar to that of $M$. smegmatis than $M$. tuberculosis. This strongly indicates that, unlike the $M$. tuberculosis/M. bovis $m a b A$-inh $A$ operon, $m a b A$ and inhA are independently transcribed in $M$. avium as in M. smegmatis. This is consistent with the previous observation that the $M$. avium mabA-inhA plasmids confer a similar level of resistance to INH and ETH as $M$. smegmatis mabAinhA plasmids, which is considerably higher than the resistance conferred by the plasmids from $M$. tuberculosis and M. bovis (Banerjee et al., 1994). These gene organization data also correlate well with similar MICs for INH in $M$. smegmatis and $M$. avium, which are much higher than the MICs of M. tuberculosis complex. Moreover, like the $M$. smegmatis ORF, the M. avium mabA ORF was found to be longer (765 bp, $255 \mathrm{aa})$ than that of M. tuberculosis and M. bovis (741 bp, $247 \mathrm{aa}$ ). In $M$. smegmatis, the reading frame probably starts with an ATG, although there is a possible GTG start site present two codons downstream. The hypothetical ATG start codon gives a size conservation ( $255 \mathrm{aa}$ ) between the MabAs of M. smegmatis and M. avium. There are significant differences between the DNA sequences in the region upstream of the mabA ORFs as well as in the beginning of the ORFs.

\section{Conservation of mabA and MabA among different mycobacteria}

As in inhA (Banerjee et al., 1994), we found that the DNA sequence of the mabA gene from $M$. tuberculosis is identical to that of M. bovis BCG (Fig. 1); we will therefore refer to these two genes as $M$. tuberculosis $m a b A$. Despite the difference in gene organization and translational start site, the $m a b A$ gene appears to be highly conserved between different mycobacteria. At the DNA level, the identity was approximately $80 \%$ (Fig. $1)$, which is in agreement with the high degree of homology indicated by the Southern blot using a fragment containing mabA. In all the 11 mycobacteria tested thus far, including important pathogens like Mycobacterium leprae, M. avium and Mycobacterium intracellulare, bands hybridizing with the M. smegmatis $m a b A$ probe were observed (data not shown). Such conservation of mabA among various mycobacteria is consistent with our repeated failure to produce a knockout of this gene in $M$. smegmatis. However, the chromosomal gene could easily be knocked out when an extra episomal copy was present (data not shown). These results indicate that MabA is likely to be essential, like InhA.

At the amino acid level (Fig. 2) the homology was even greater ( $82-85 \%$ identity). Expectedly, M. tuberculosis MabA shows stronger homology to $M$. avium MabA than the $M$. smegmatis protein, since the former two organisms share a closer ancestry. Additionally, the similarity score, indicating amino acid residue conservation between the MabAs, is about $88-90 \%$. Apart from the first few residues of the reading frames, homology is uniform throughout the protein sequence. All the MabA peptides contain an NADP-binding consensus sequence GXGXXAXXXAXXXXXXG (Hanukoglu \& Gutfinger, 1989). 


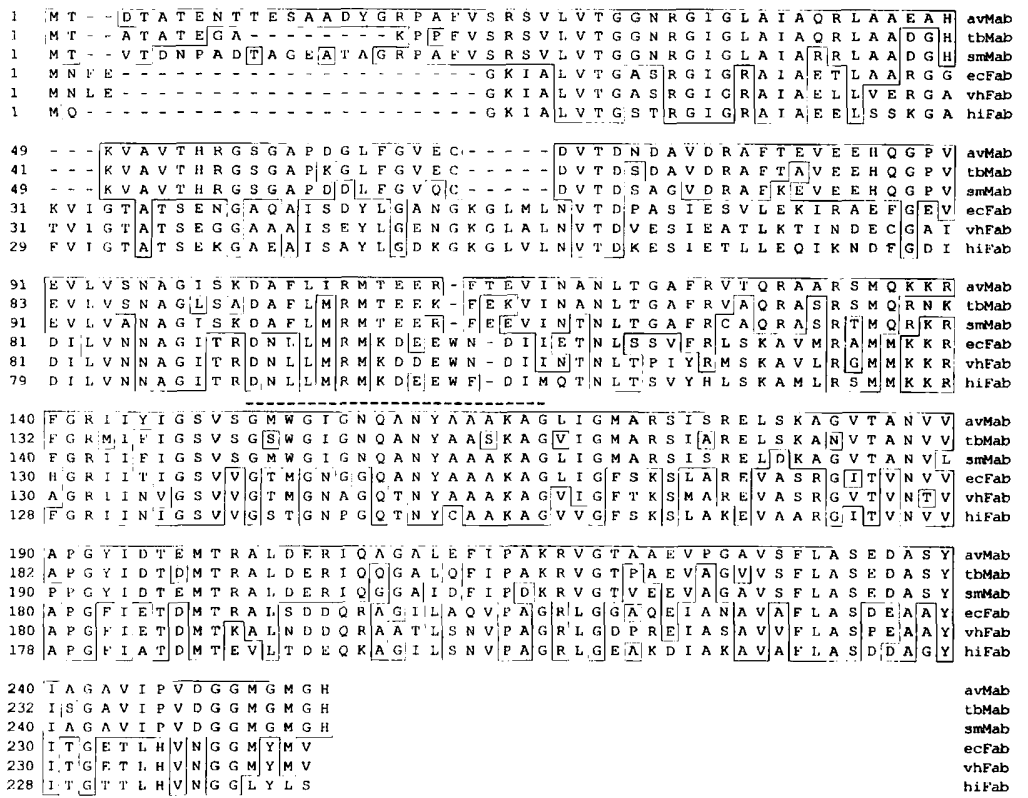

Fig. 2. Comparison of amino acid sequences of the mycobacterial MabA polypeptide with the KAR or fabG gene-product of $E$. coli, $H$. influenzae and $V$. harveyi. From top to bottom, the sequences presented are MabAs from $M$. avium (avMab), $M$. tuberculosis (tbMab) and $M$. smegmatis (smMab), and KARs from E. coli (ecFab), V. harveyi (vhFab) and $H$. influenzae (hiFab). The comparison was performed using the Jotun-Hein algorithm of the Megalign program of Lasergene software package from DNAstar. The boxes indicate identical amino acids. The putative NADPH-binding GXG$X X A X X X A X X X X X X G$ consensus sequence (Hanukoglu \& Gutfinger, 1989) is indicated by a dashed overline.

\section{Homology of MabA amino acid sequence with other KARs that are available in the database}

A tFasta (Genetics Computer Group, 1995) search was performed on the EMBL and GenBank databases, using both the amino acid sequences. The search revealed that the best homologies to MabA are KARs from E. coli (Rawlings \& Cronan, 1992), Vibrio harveyi (Shen \& Byers, 1996) and Haemophilus influenzae (Fleischmann et al., 1995). The sequence alignment of these three fatty acid biosynthesis enzymes with the three MabA sequences is shown in Fig. 2. The identity between the MabAs and the KARs is approximately $40 \%$ and the total similarity is about $60 \%$. In addition, the KAR counterparts from plants, the $\beta$-ketoacyl-ACP reductases of Cuphea lanceoleta (Klein et al., 1992), Arabdopsis thaliana and Brassica napus (Slabas et al., 1992), show strong homology ( $\sim 35-40 \%$ identity) to the two MabA sequences.

\section{Overexpression of MabA and biochemical determination of its activity}

The $744 \mathrm{bp}$ insert in the pET3d-mabA construct was verified by sequencing and found to match the wild-type $m a b A$ sequence. To verify the function of the reading frame in the construct, pET3d-mabA was transformed into BL21(DE3)pLysS, a lysogenic strain containing the gene for T7 RNA polymerase under the control of a lacUV5 promoter. Cell-free extracts made from cultures after $2.5 \mathrm{~h}$ with or without induction by $1 \mathrm{mM}$ IPTG were examined by PAGE. The IPTG-induced cells harbouring pET3d-mabA showed moderate overexpression of a $28 \mathrm{kDa}$ protein (data not shown) which matched the predicted molecular mass of $25665 \mathrm{Da}$. This protein band was not seen in extracts of uninduced cells or control cells without plasmids.

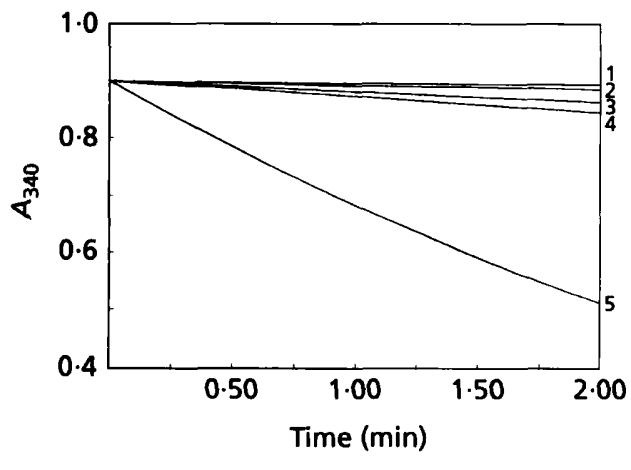

Fig. 3. Characterization of the enzymic activity of MabA protein from $M$. tuberculosis. Continuous scan assay of relative KAR activity using NADH or NADPH as cofactor in the presence or absence of IPTG induction. $A_{340}$ is plotted as a function of reaction time for (1) induced culture with NADPH but without acetoacetyl-CoA, (2) uninduced cell extract + NADH, (3) uninduced cell extract + NADPH, (4) induced cell extract + NADH and (5) induced cell extract + NADPH.

The soluble extracts from both induced and uninduced strains were assayed for KAR activity. The extracts were tested in the presence of either NADH or NADPH. By a continuous scanning spectrophotometric assay, using both cofactors, the extracts from the induced cells were found to have considerable KAR activity (Fig. 3). However, the enzyme demonstrated a definite preference for NADPH, as seen by the sevenfold increase in activity in the presence of this substrate. This definite preference for NADPH agrees with the presence of an NADPbinding motif (Hanukoglu \& Gutfinger, 1989) in MabA (Fig. 2). The extract from the uninduced cells showed no significant activity although there could be some back- 


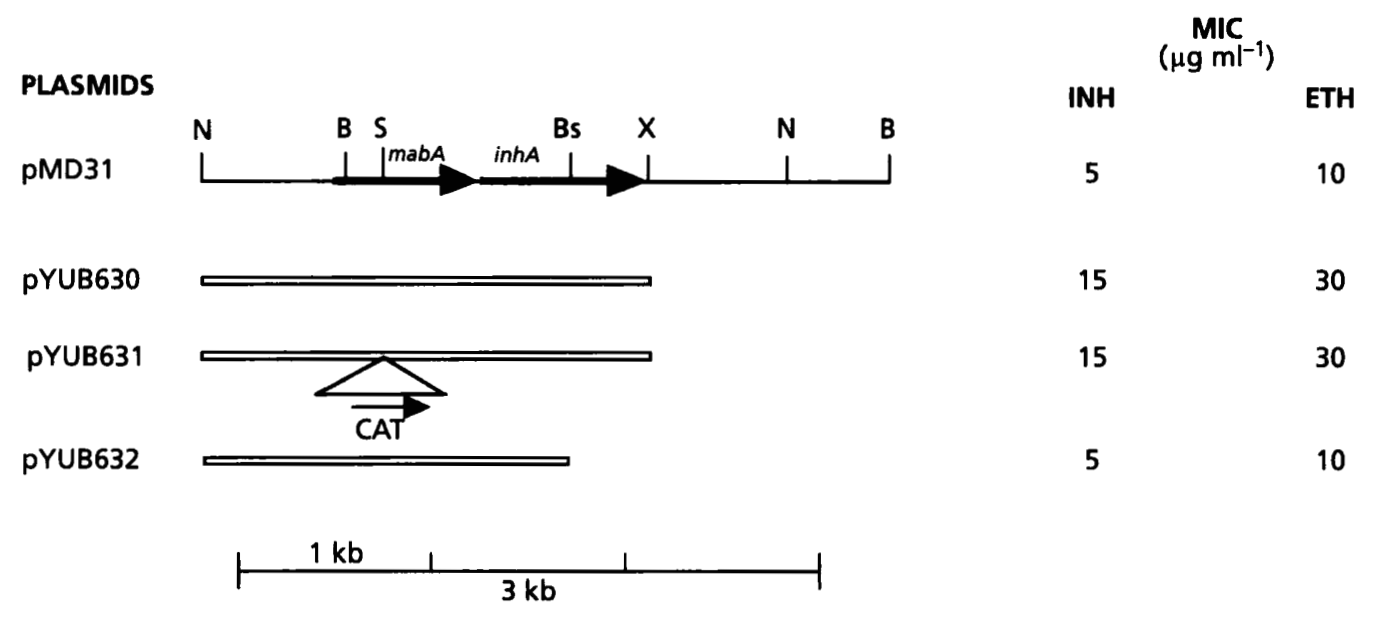

Fig. 4. Subcloning analysis to determine whether mabA from $M$. tuberculosis can confer resistance to INH and ETH. The top line indicates the inhA-mabA locus. The solid arrows indicate the ORFs and the thin line indicates noncoding regions. The open bars represent different restriction fragments of $M$. tuberculosis DNA that were cloned into the vector pMD31. B, BamHI; Bs, BsaBI; N, Nhel; S, Sphl; X, Xbal. The orientation of the CAT gene in pYUB631 is indicated by an arrow.

ground activity from the E. coli KAR. The host activity is probably not observed because the E. coli KAR, which preferentially uses acetoacetyl-ACP, has been reported to have very poor activity with acetoacetyl-CoA as substrate (Toomey \& Wakil, 1966). In addition, induction of this activity by IPTG clearly distinguished the KAR of $M$. tuberculosis from any background contaminant from the $E$. coli host or other contaminating activities in the extract. The activity tests were then repeated with increasing concentrations of the induced extract and demonstrated a linear dependence (data not shown) of activity on the amount of the induced extract (i.e. MabA protein concentration) to further support the claim that the observed KAR activity is indeed from the induced MabA protein.

\section{Examination of the multiple copy effect of $M$. tuberculosis mabA on INH-ETH resistance}

New plasmids were constructed based on the mycobacteria-E. coli shuttle vector pMD31 (Donnelly-Wu et al., 1993) to separate mabA from inhA (Fig. 4). The first of these new plasmids, pYUB630, is a derivative of a previously published plasmid, pYUB376 (Table 1). It contains the entire mabA-inbA locus but none of the extra DNA present $3^{\prime}$ of inhA in PYUB376 and it confers the INH-ETH-resistance phenotype in the M. smegmatis $\mathrm{mc}^{2} 155$ host by raising the $\mathrm{MIC}_{\mathrm{INH}}$ to $15 \mu \mathrm{g} \mathrm{m}^{-1}$ and $\mathrm{MIC}_{\text {ETH }}$ to $30 \mu \mathrm{g} \mathrm{ml}^{-1}$ from the wild-type values of $5 \mu \mathrm{g} \mathrm{ml}^{-1}$ and $10 \mu \mathrm{g} \mathrm{m}^{-1}$ (Fig. 4). A chloramphenicol acetyltransferase (CAT) cassette (Bartolome et al., 1991) was inserted into mabA in pYUB630. The CAT fragment is known to be nonpolar and does not carry any terminator of transcription. Hence, this insertion should not interfere with the expression of inbA. This construct with a defective mabA but a wild-type $\operatorname{inh} A$ was designated pYUB631. When introduced into $\mathrm{mc}^{2} 155$, pYUB631 conferred the same resistance phenotype as
pYUB630. pYUB632 contains a wild-type $m a b A$ and a truncated inhA. This plasmid failed to confer any drug resistance upon the host. The cloning vector pMD31 by itself did not confer any resistance to INH and ETH when introduced into $\mathrm{mc}^{2} 155$. In addition, pYUB632 was tested in M. bovis BCG, where it also failed to show any enhanced resistance over the pMD31 vector control $\left(\mathrm{MIC}_{\mathrm{INH}} 0.2 \mu \mathrm{g} \mathrm{ml}^{-1}\right)$.

The results discussed above clearly show that interruption of $M$. tuberculosis $m a b A$ without affecting inh $A$ does not interfere with the ability of the plasmid to confer INH-ETH resistance. However, a deletion of the inb $A$ locus while keeping mabA intact causes a complete loss of the resistance phenotype. Therefore, unlike the overexpression of $M$. tuberculosis InhA, the overexpression of MabA from $M$. tuberculosis does not show the ability to titrate INH and ETH.

\section{DISCUSSION}

In M. tuberculosis and M. bovis, mabA and inhA are in one operon whereas in $M$. smegmatis (and probably in $M$. avium) these two genes are independently transcribed (Banerjee et al., 1994). As discussed in the Introduction, MabA from M. tuberculosis was suggested as a possible target for $\mathrm{INH}$, mainly due to frequent observations of mutations at the RBS of $m a b A$ in many clinical INH-resistant $M$. tuberculosis isolates (Musser, 1995). This hypothesis was further supported by the unique mabA-inbA operon arrangement in the INH-sensitive $M$. tuberculosis complex, the similarity in the degree of MabA conservation with InhA conservation among different mycobacteria and the probable essential nature of MabA activity. Additionally, this possibility was supported by a biochemical study on $M$. avium (Kikuchi et al., 1989) which reported that INH inhibits a KAR in addition to an ER. This KAR, like 
MabA, was demonstrated to prefer NADPH over $\mathrm{NADH}$ and was reported to have specific involvement in mycolic acid synthesis. Although a direct involvement of MabA in mycolate synthesis could not be tested due to our inability to procure or synthesize a long-chain substrate for the KAR assay, mabA probably synthesizes mycolic acid because it forms an operon with inhA, which has been shown to be involved in mycolate synthesis (Quemard et al., 1995; Wheeler \& Anderson, 1996). Finally, in M. tuberculosis, there is room for the presence of other INH target(s) besides InhA because the MIC for the M. tuberculosis complex is considerably lower (25- to 100-fold) than that of M. smegmatis (Banerjee et al., 1994; Zhang et al., 1992) even though InhAs from these organisms are highly conserved. Hence, it became imperative to test the role of MabA in INH resistance.

It has recently been clearly demonstrated that INH reacts with $\mathrm{NADH}$, the preferred cofactor for InhA, to form isonicotinic acyl-NADH inside the active site of InhA (Rozwarski et al., 1998). This reaction, catalysed by $\mathrm{KatG}$ and $\mathrm{Mn}^{2+}$, blocks the ER activity of the protein. ETH is proposed to bind InhA by a similar, but different, mechanism. These observations support the earlier hypothesis (Banerjee et al., 1994) that overexpression of InhA can titrate additional active INH (i.e. isonicotinic acyl-NADH) and thereby increase the MIC or the level of resistance. However, data discussed in this manuscript show that overexpression of MabA from $M$. tuberculosis does not confer the ability to titrate either INH or ETH. This rules out the possibility of MabA being a direct target in vivo for an active INH like isonicotinic acyl-NADH/NADPH. This conclusion is consistent with the fact that, until now, no mutations have been mapped to the MabA ORF in INH-resistant organisms. In contrast, mutations have been mapped to the mabA RBS with high frequency and also in the InhA ORF with lower, but significant, frequency (Banerjee $e t$ al., 1994; Ristow et al., 1995; Kapur et al., 1996, Rozwarski et al., 1998). Additionally, a report using single-copy integrating vectors demonstrated that the mutations in the mabA RBS actually led to overexpression of InhA (Mdluli et al., 1996). However, the authors concluded from their drug sensitivity assays that these mutations play no role in INH resistance. Nonetheless, on close scrutiny of their data, we see that these mutations conferred a clear increase in INH resistance, particularly at the level corresponding to the MIC of $M$. tuberculosis. Hence, we propose that mutations in the RBS of mabA mediate INH resistance in M. tuberculosis by overexpression of the InhA protein through transcriptional upregulation of the whole inh $A$ operon and not by specific translational upregulation of MabA. This hypothesis is consistent with the fact that hundreds of INH-resistant strains from different parts of the world demonstrated mabA RBS mutations but none of many INH-sensitive strains screened have demonstrated these mutations (Musser et al., 1996).

In addition, the observation of INH-induced inhibition of both KAR and ER in the in vitro system of Kikuchi et al. (1989) is not necessarily contradictory to our hypothesis of MabA not being a direct and primary target of INH in vivo. These two systems are very different. In the in vitro system, KAR and ER were assayed for INH inhibition in semi-defined extracts. It is completely unknown whether those fractions contained some, or any, $\mathrm{KatG}$ and $\mathrm{Mn}^{2+}$. Moreover, the concentration of $\mathrm{INH}$ is much higher in the in vitro assay. All these important and many more subtle disagreements between the in vitro and the in vivo systems may make the mechanism of action of the in vitro system different from the in vivo model. Hence, given the complex nature of the INH mode of action, an undefined in vitro assay may not represent the actual in vivo environment.

Finally, cloning and characterization of MabA may also help in the future development of antimycobacterial therapeutics. Characterization of InhA activity and knowledge of its three-dimensional structure have generated a structure-function-based approach to design new antimycobacterial compounds (Rozwarski et al., 1998) and broad-spectrum antibiotics (Baldock et al., 1996). Similarly, the knowledge of the MabA activity together with the ability to overexpress this highly conserved protein presents the mabA-encoded KAR as a potential target for developing new drugs. Additionally, further biochemical and structural characterization of this KAR may also lead to greater insight into the as yet unknown but important biology of mycolic acid biosynthesis.

\section{ACKNOWLEDGEMENTS}

We thank Drs Emil C. Gotschlich and Vijay K. Pancholi for their critical review of this manuscript. This study was supported by a grant from the National Institute of Health (AI 27160).

\section{REFERENCES}

Baldock, C., Rafferty, J. B., Sedelnikova, S. E., Baker, P. J., Stuitje, A. R., Slabas, A. R., Hawkes, T. R. \& Rice, D. W. (1996). A mechanism of drug action revealed by structural studies of enoyl reductase. Science 274, 2107-2110.

Banerjee, A., Dubnau, E., Quemard, A., Balasubramanian, V., Um, K. S., Wilson, T., Collins, D., de Lisle, G. \& Jacobs, W. R., Jr (1994). inh $A$, a gene encoding a target for isoniazid and ethionamide in Mycobacterium tuberculosis. Science 263, 227-230.

Bartolome, B., Jubete, Y., Martinez, E. \& De La Cruz, F. (1991). Construction and properties of a family of pACYC184-derived cloning vectors compatible with pBR322 and its derivatives. Gene 102, 75-78.

Dessen, A., Quemard, A., Blanchard, J. S., Jacobs, W. R., Jr \& Sacchettini, J. C. (1995). Crystal structure and function of the isoniazid target of Mycobacterium tuberculosis. Science 267, 1638-1641.

Donnelly-Wu, M. K., Jacobs, W. R., Jr \& Hatfull, G. F. (1993). Superinfection immunity of mycobacteriophage L5: applications for genetic transformation of mycobacteria. Mol Microbiol 7, 407-417.

Fleischmann, R. D., Adams, M. D., White, O. \& 37 other authors (1995). Whole-genome random sequencing and assembly of Haemophilus influenzae Rd. Science 269, 496-512. 
Genetics Computer Group (1995). Program Manual: Wisconsin Sequence Analysis Package, Version 8, UNIX. Madison, WI: Genetics Computer Group, Madison.

Hanukoglu, I. \& Gutfinger, T. (1989). cDNA sequence of adrenodoxin reductase. Identification of NADP-binding sites in oxidoreductases. Eur J Biochem 180, 479-484.

Heym, B., Honore, N., Truffot-Pernot, C., Banerjee, A., Schurra, C., Jacobs, W. R., Jr, van Embden, J. D., Grosset, J. H. \& Cole, S. T. (1994). Implications of multidrug resistance for the future of chemotherapy of tuberculosis: a molecular study. Lancet 344, 293-298.

Jacobs, W. R., Jr, Kalpana, G. V., Cirillo, J. D., Pascopella, L., Snapper, S. B., Udani, R., Jones, W., Barletta, R. G. \& Bloom, B. R. (1991). Genetic systems for mycobacteria. Methods Enzymol 204, 537-555.

Johnsson, K., King, D. S. \& Schultz, P. G. (1995). Studies on the mechanism of action of isoniazid and ethionamide in the chemotherapy of tuberculosis. J Amer Chem Soc 117, 5009-5010.

Kapur, V., Li, L. L., Hamrick, M. R. \& 11 other authors (1996). Rapid mycobacterium species assignment and unambiguous mutations associated with antimicrobial resistance in $\mathrm{Myco-}$ bacterium tuberculosis. Arch Pathol Lab Med 119, 131-138.

Kikuchi, S., Takeuchi, T., Yasui, M., Kusaka, T. \& Kolattukudy, P. E. (1989). A very long-chain fatty acid elongation system in Mycobacterium avium and a possible mode of action of isoniazid on the system. Agric Biol Chem 53, 1689-1698.

Klein, B., Pawlowski, K., Horicke-Grandpierre, C., Schell, J. \& Topfer, R. (1992). Isolation and characterization of a cDNA from Cuphea lanceolata encoding a $\beta$-ketoacyl-ACP reductase. $\mathrm{Mol}$ Gen Genet 233, 122-128.

Mdluli, K., Sherman, D. R., Hickey, M. J., Kreiswirth, B. N., Morris, S., Stover, C. K. \& Barry, C. E. (1996). Biochemical and genetic data suggest that InhA is not the primary target for activated isoniazid in Mycobacterium tuberculosis. J Infect Dis 174, 1085-1090.

Musser, J. M. (1995). Antimicrobial agent resistance in mycobacteria - molecular genetic insights. Clin Microbiol Rev 8, 496-514

Musser, J. M., Kapur, V., Williams, D. L., Kreiswirth, B. N. \& Vansoolingen, D. (1996). Characterization of the catalase-peroxidase gene (katG) and inhA locus in isoniazid-resistant and -susceptible strains of Mycobacterium tuberculosis by automated DNA sequencing - restricted array of mutations associated with drug resistance. J Infect Dis 173, 196-202.

Quemard, A., Sacchettini, J. C., Dessen, A., Vilcheze, C., Bittman, R., Jacobs, W. R., Jr \& Blanchard, J. S. (1995). Enzymatic characterization of the target for isoniazid in Mycobacterium tuberculosis. Biochemistry 34, 8235-8241.

Rawlings, M. \& Cronan, J. E., Jr (1992). The gene encoding Escherichia coli acyl carrier protein lies within a cluster of fatty acid biosynthetic genes. J Biol Chem 267, 5751-5754.

Ristow, M., Mohlig, M., Rifai, M., Schatz, H., Feldmann, K. \& Pfeiffer, A. (1995). New isoniazid/ethionamide resistance gene mutation and screening for multidrug-resistant Mycobacterium tuberculosis strains. Lancet 346, 502-503.

Rouse, D. A., Li, Z. M., Bai, G. H. \& Morris, S. L. (1995). Characterization of the kat $G$ and inhA genes of isoniazid-resistant clinical isolates of Mycobacterium tuberculosis. Antimicrob Agents Chemother 39, 2472-2477.
Rozwarski, D. A., Grant, G. A., Barton, D. H. R., Jacobs, W. R., Jr \& Sacchettini, J. C. (1998). Modification of the NADH of the isoniazid target (InhA) from Mycobacterium tuberculosis. Science 278, 98-102.

Sambrook, J., Fritsch, E. F. \& Maniatis, T. (1989). Molecular Cloning: a Laboratory Manual, 2nd edn. Cold Spring Harbor, NY: Cold Spring Harbor Laboratory.

Shen, Z. W. \& Byers, D. M. (1996). Isolation of Vibrio harveyi acyl carrier protein and the $f a b G, a c p P$, and $f a b F$ genes involved in fatty acid biosynthesis J Bacteriol 178, 571-573.

Slabas, A. R., Chase, D., Nishida, I. \& 7 other authors (1992). Molecular cloning of higher-plant 3-oxoacyl-(acyl carrier protein) reductase. Sequence identities with the nodG-gene product of the nitrogen-fixing soil bacterium Rhizobium meliloti. Biochem $J$ 283, 321-326.

Snapper, S. B., Melton, R. E., Mustafa, S., Kieser, T. \& Jacobs, W. R., Jr (1990). Isolation and characterization of efficient plasmid transformation mutants of Mycobacterium smegmatis. Mol Microbiol 4, 1911-1919.

Snider, D. E., Raviglione, M. \& Kochi, A. (1994). Global burden of tuberculosis. In Tuberculosis: Pathogenesis, Protection, and Control, pp. 3-12. Edited by B. R. Bloom. Washington, DC: American Society for Microbiology.

van Soolingen, D., Hermans, P. W., de Haas, P. E., Soll, D. R. \& van Embden, J. D. (1991). Occurrence and stability of insertion sequences in Mycobacterium tuberculosis complex strains : evaluation of an insertion sequence-dependent DNA polymorphism as a tool in the epidemiology of tuberculosis. Clin Microbiol 29, 2578-2586.

Studier, F. W., Rosenberg, A. H., Dunn, J. J. \& Dubendorff, J. W. (1990). Use of T7 RNA polymerase to direct expression of cloned genes. Methods Enzymol 185, 60-89.

Telenti, A., Honore, N., Bernasconi, C., March, J., Ortega, A., Heym, B., Takiff, H. E. \& Cole, S. T. (1997). Genotypic assessment of isoniazid and rifampin resistance in Mycobacterium tuberculosis: a blind study at reference laboratory level. J Clin Microbiol 35, 719-723.

Toomey, R. E. \& Wakil, S. J. (1966). Studies on the mechanism of fatty acid synthesis. XV. Preparation and general properties of $\beta$ ketoacyl acyl carrier protein reductase from Escherichia coli. Biochim Biophys Acta 116, 189-197.

Victor, T. C., Warren, R., Butt, J. L. \& 9 other authors (1997). Genome and MIC stability in Mycobacterium tuberculosis and indications for continuation of use of isoniazid in multidrugresistant tuberculosis J Med Microbiol 46, 847-857.

Wheeler, P. R. \& Anderson, P. M. (1996). Determination of the primary target for isoniazid in mycobacterial mycolic acid biosynthesis with Mycobacterium aurum A+. Biochem J 318, $451-457$.

World Health Organization (1997). The World Health Report 1997. Geneva, Switzerland: World Health Organization.

Zhang, Y., Heym, B., Allen, B., Young, D. \& Cole, S. (1992). The catalase-peroxidase gene and isoniazid resistance of Mycobacterium tuberculosis. Nature 358, 591-593.

Received 23 December 1997; revised 7 April 1998; accepted 14 May 1998. 